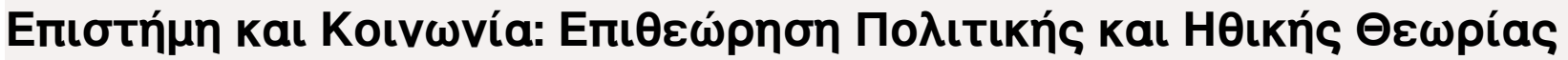

Toн. 10, 2003

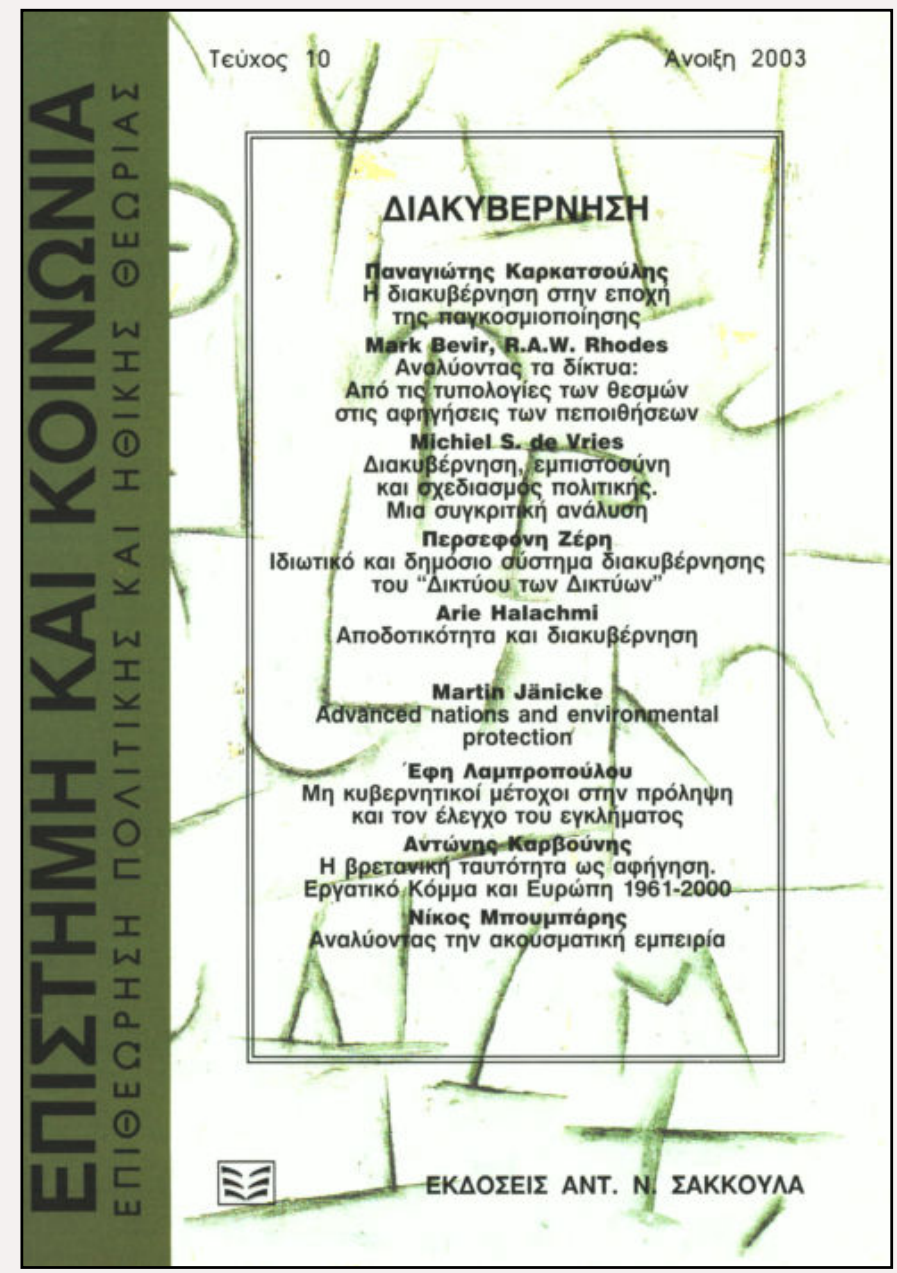

\section{Arend Lijphart, Patterns of democracy. Government forms and performance in thirty-six countries}

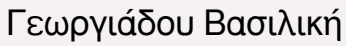

http://dx.doi.org/10.12681/sas.708

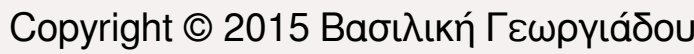

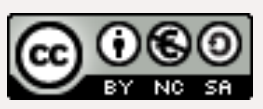

To cite this article:

$\Gamma \varepsilon \omega p y ı$ ı́dou, B. (2015). Arend Lijphart, Patterns of democracy. Government forms and performance in thirty-six

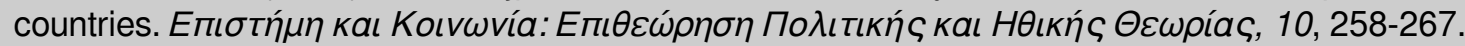

doi:http://dx.doi.org/10.12681/sas.708 
Narcotic Use in America, 1923 - 1965. Knoxville: University of Tenessee Press.

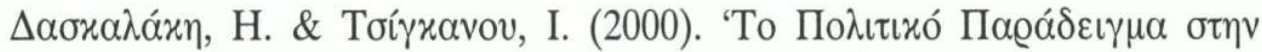

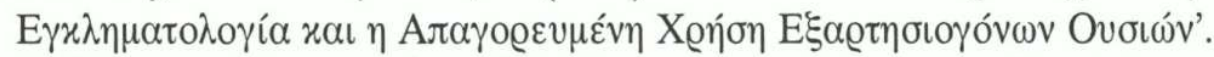

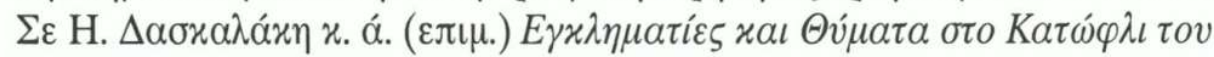

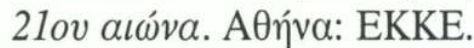

Habermas J. (1987). The Philosophical Discourse of Modernity. Cambridge: Polity Press.

Kleiman M. A. R. (1992). Against Excess: Drug Policy for Results. New York: Basic Books.

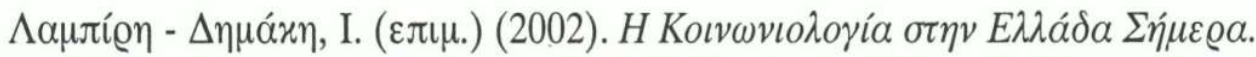

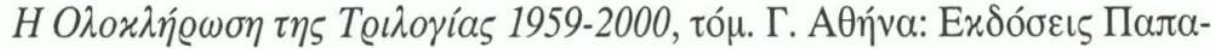
६ท́⿴囗.

Lyotard J. F. (1985). The Post-Modern Condition. Mineapolis: University of Minnesota Press.

Musto D. (1987). The American Disease: Origins of Narcotic Control. Oxford University Press.

Pearson G. (1995). Drugs, Crime and Aliens: Re-Writing Cultural History. Boston: Annual Meeting of he American Society of Criminology (November).

Pearson J. (1999). 'Drugs at the End of the Century'. The British Journal of Criminology, 39. 4.

Rosenau P.M. (1992). Post-Modernism and the Social Sciences: Insights, Inroads, Intrusions. Princeton University Press.

Arend Lijphart, Patterns of democracy. Government forms and performance in thirty-six countries, Yale University Press, New Haven and London 1999,

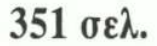

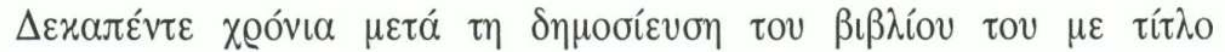

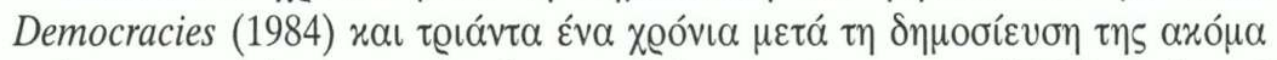

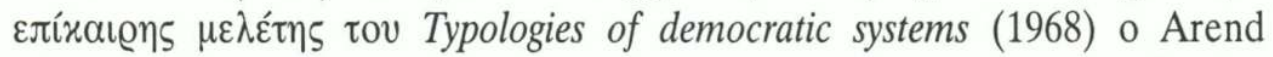

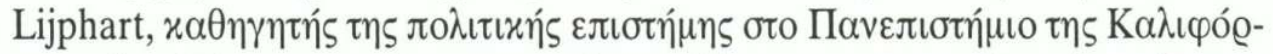

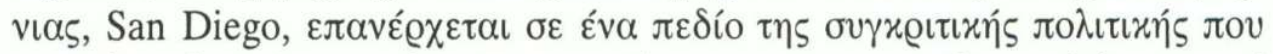

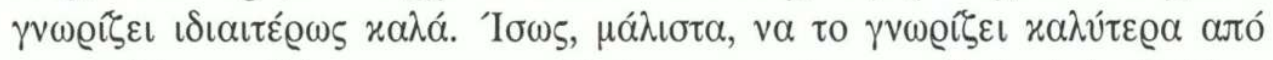

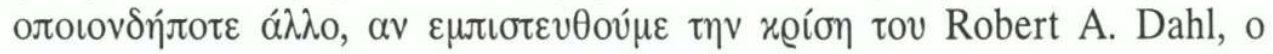

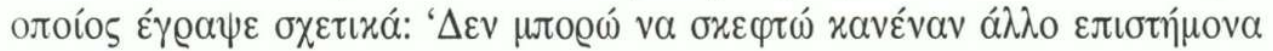




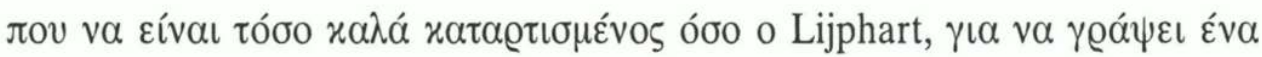

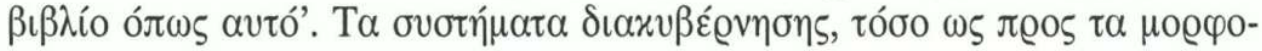

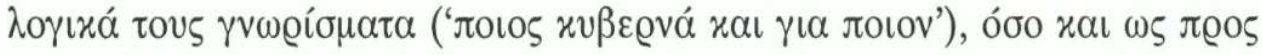

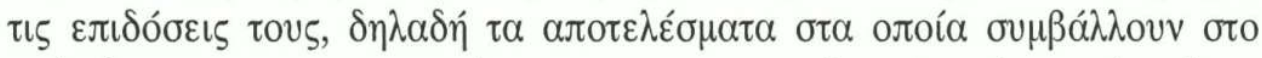

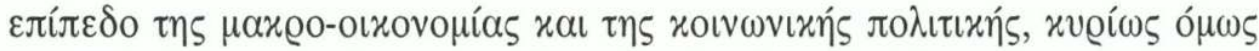

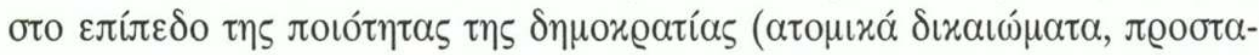

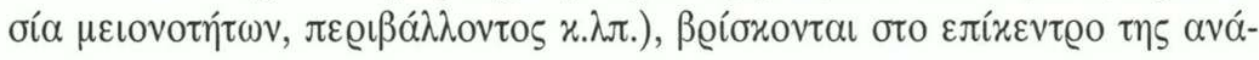

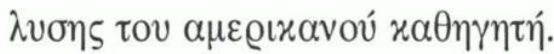

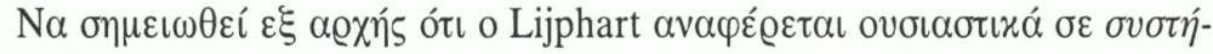

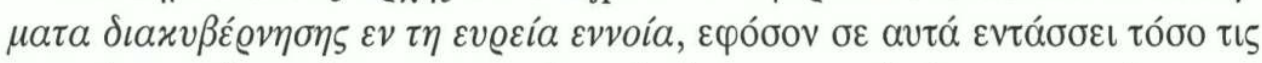

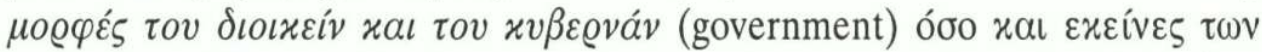

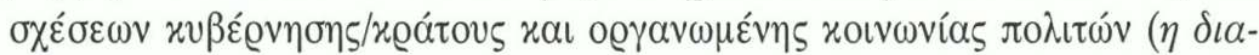

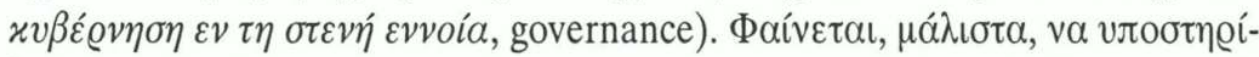

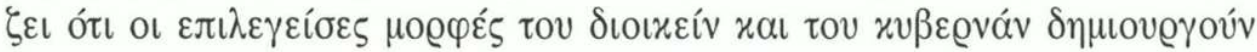

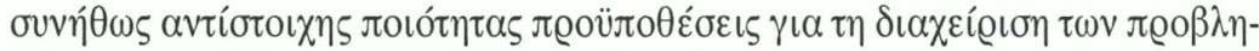

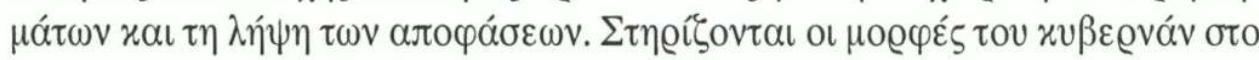

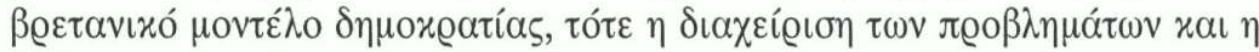
$\lambda \eta ́ \psi \eta \tau \omega v$ a

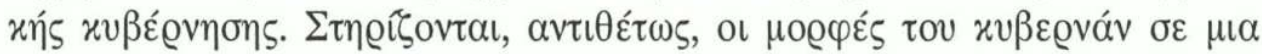

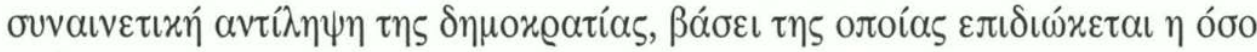

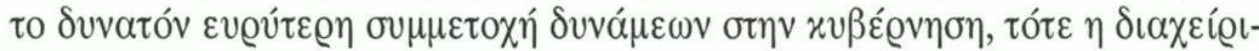

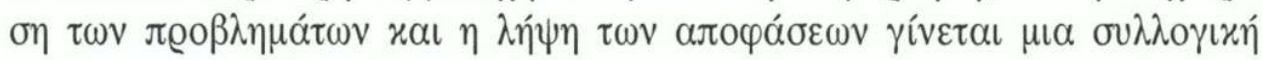

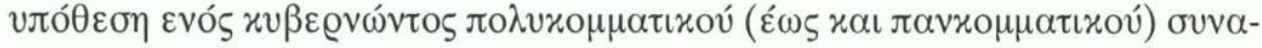

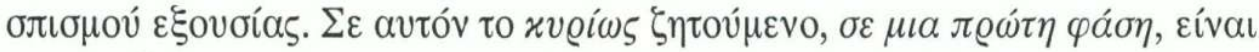

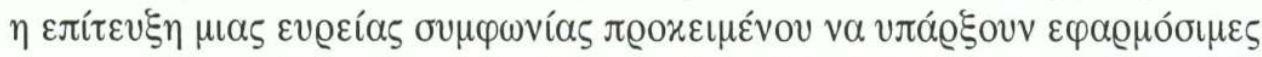

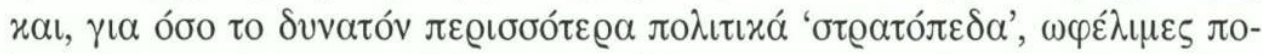

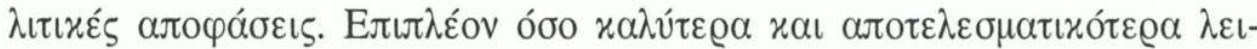

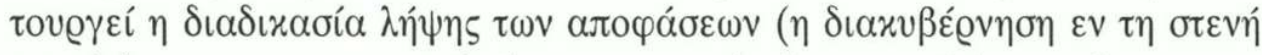

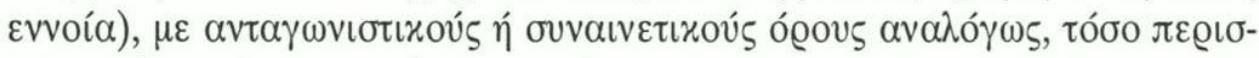

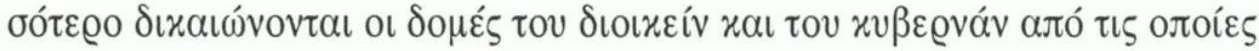

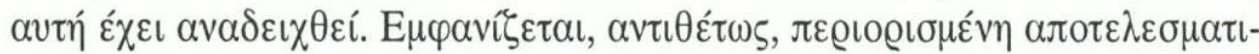

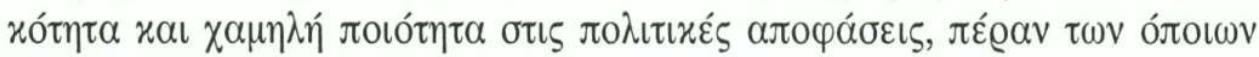
$\varepsilon \xi \omega \tau \varepsilon \varrho เ$

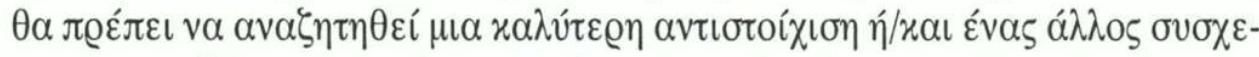

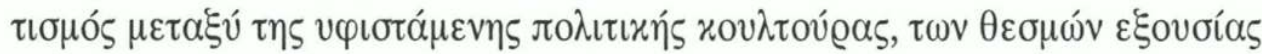

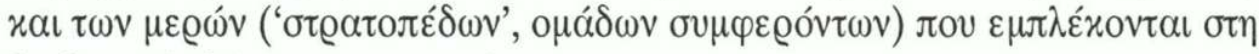
$\delta\llcorner\alpha \delta \iota x \alpha \sigma i \alpha \lambda \eta \dot{\psi} \psi \eta \varsigma \tau \omega v \alpha \pi \circ \varphi \alpha ́ \sigma \varepsilon \omega v$. 


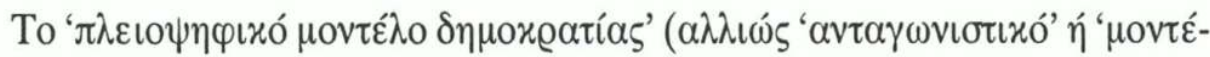

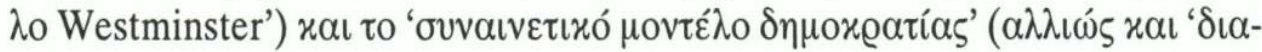

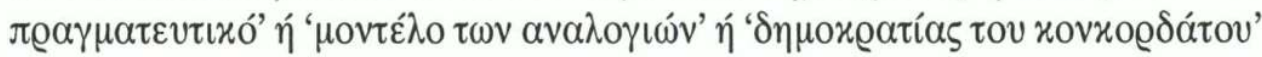

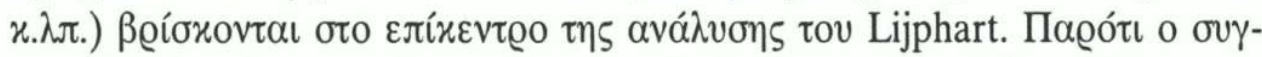

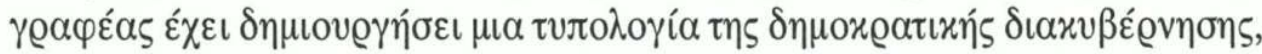

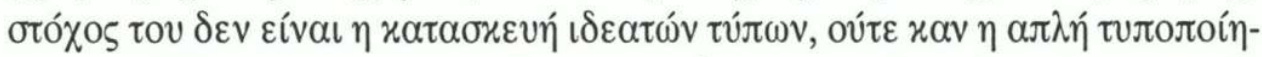

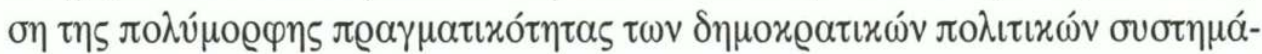

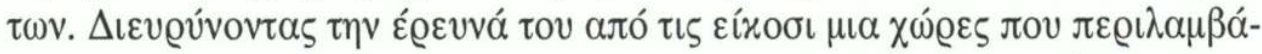

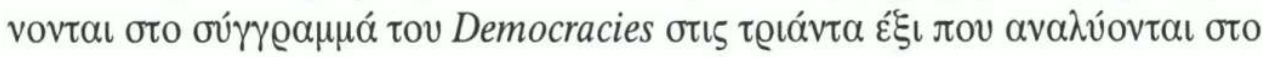

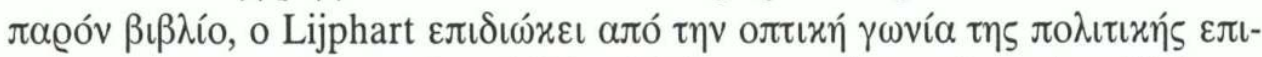

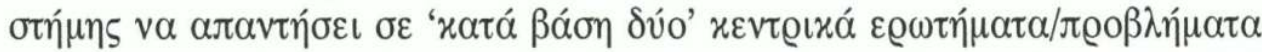

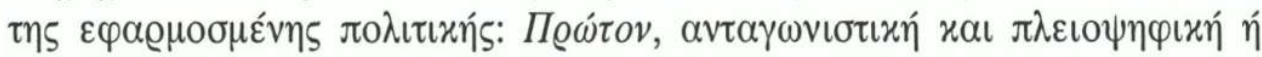

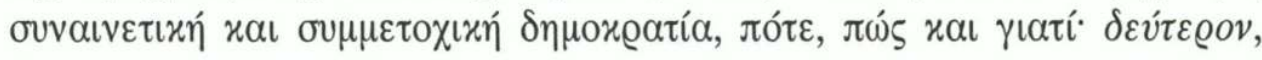

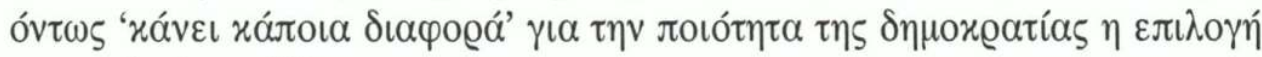

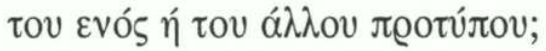

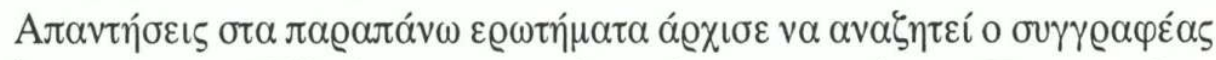

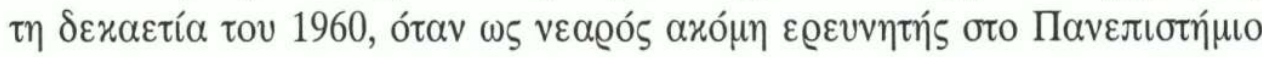

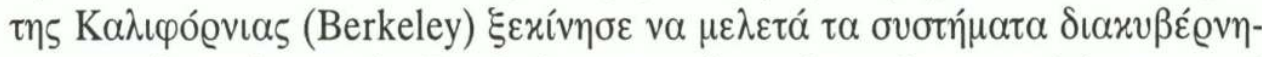

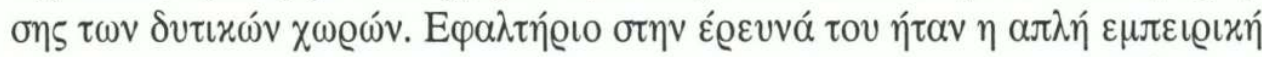

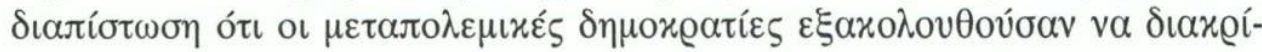

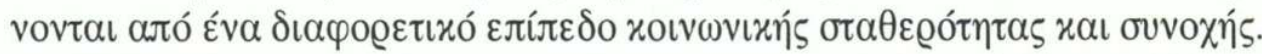

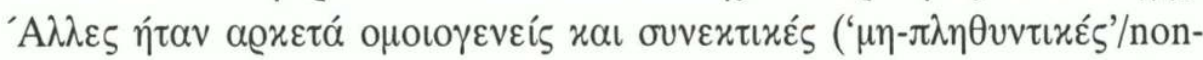

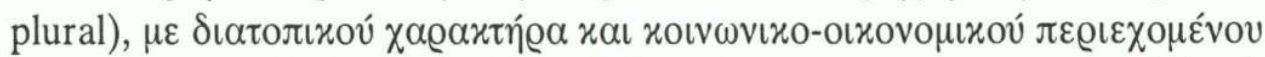

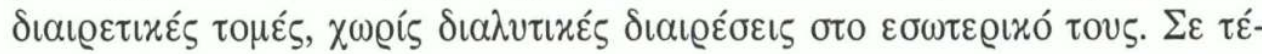

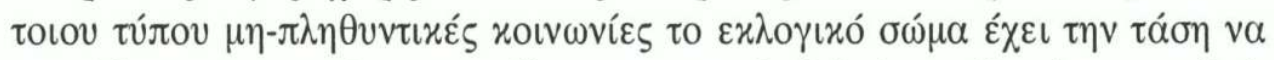

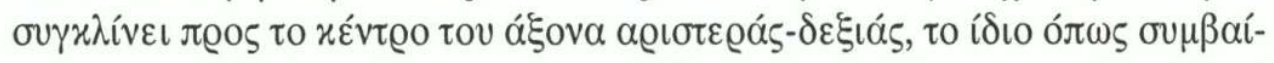

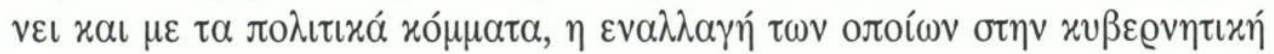

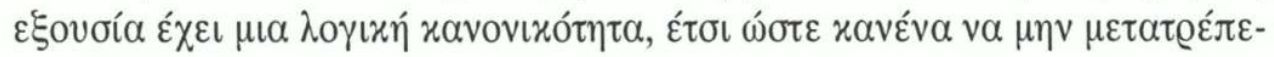

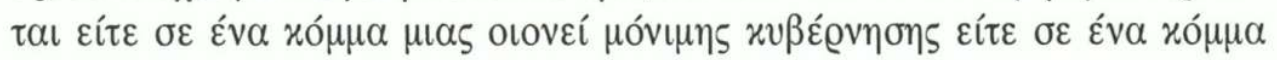

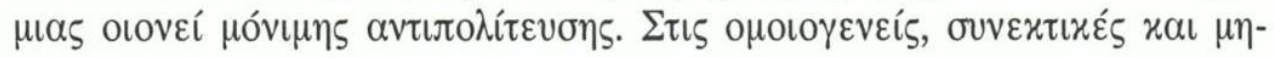

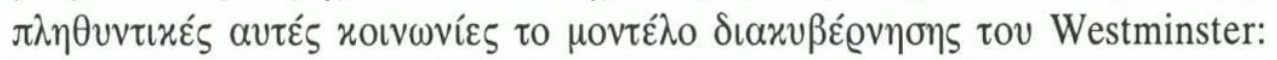

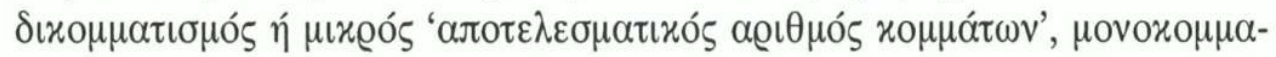

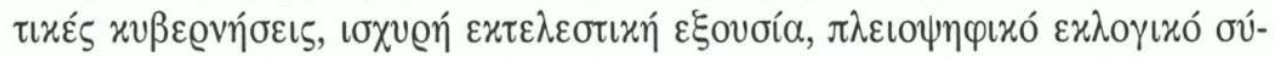

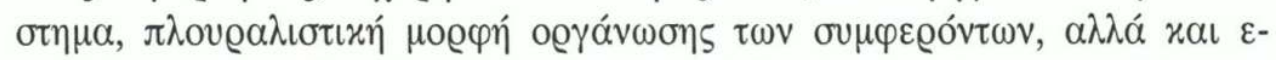

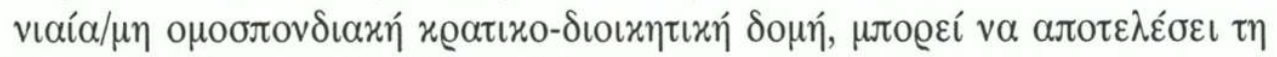

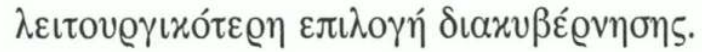

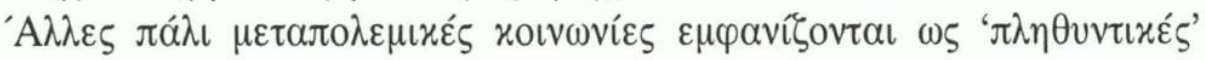




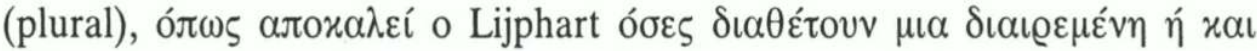

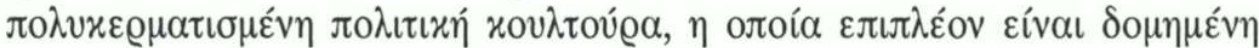

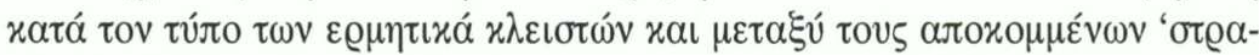

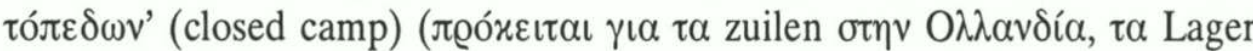

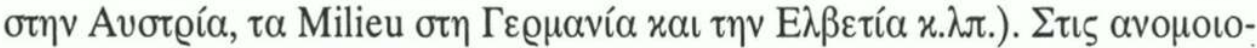

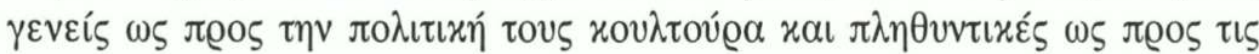

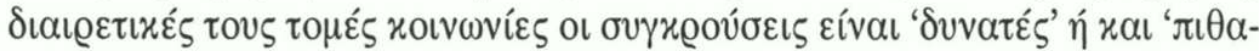

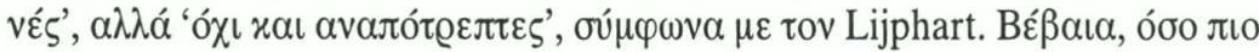

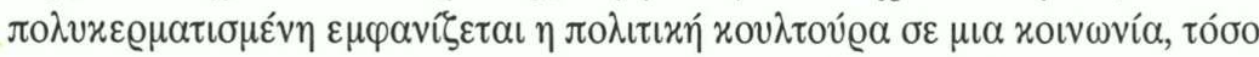

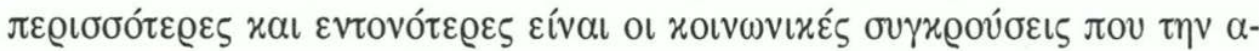

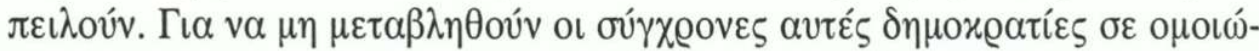

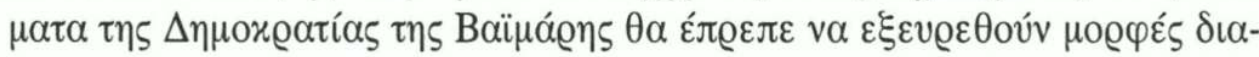

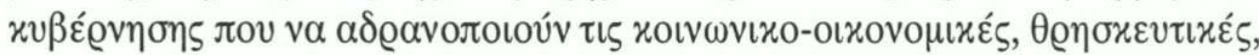

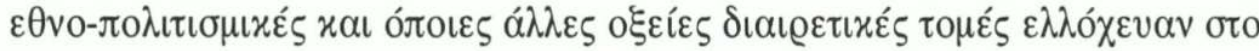

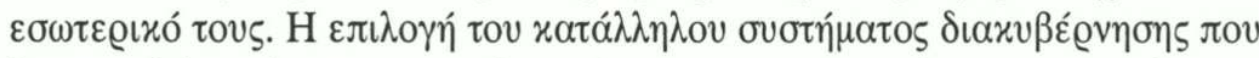

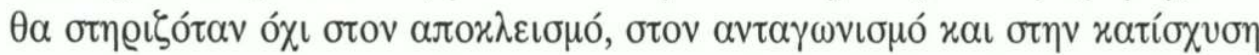

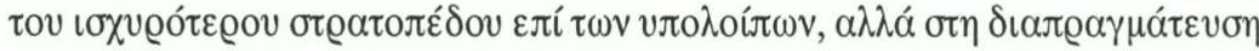

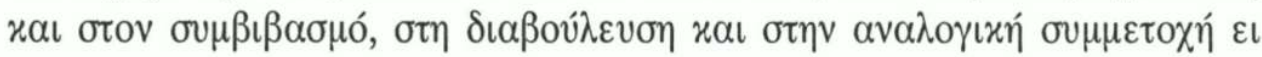

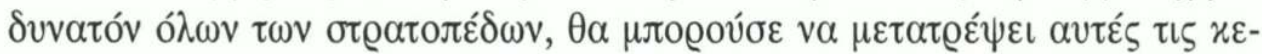

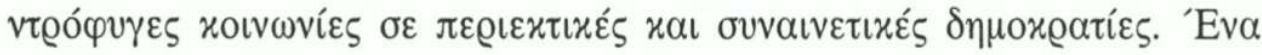

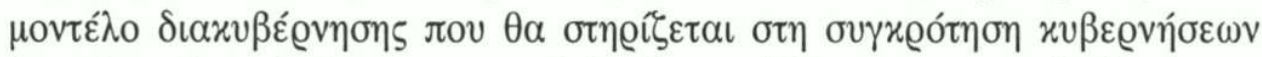

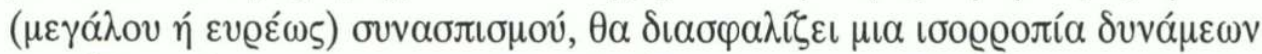

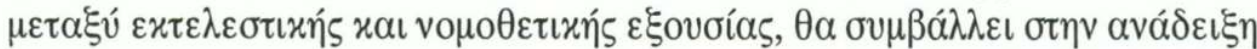

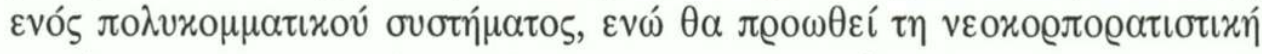

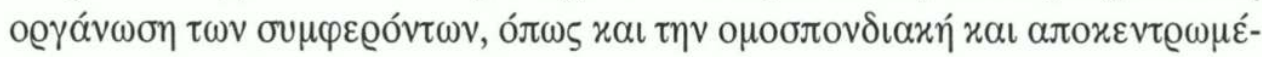

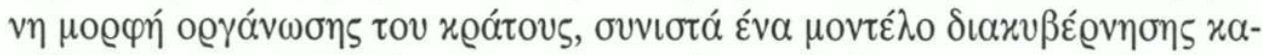

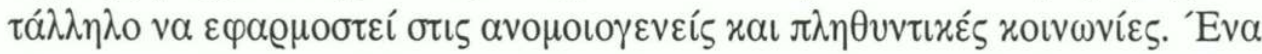

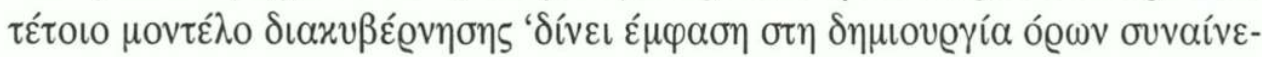

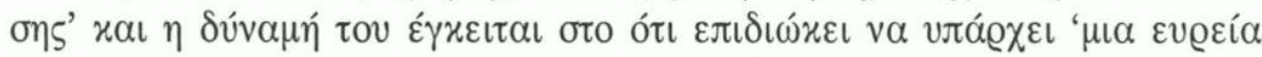

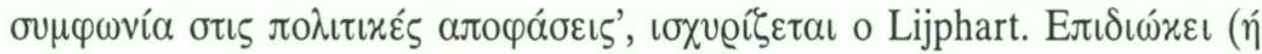

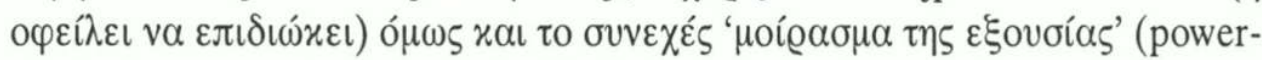

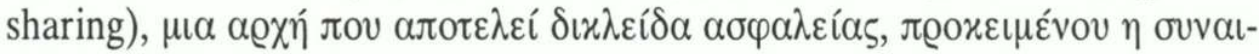

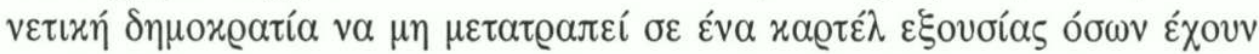

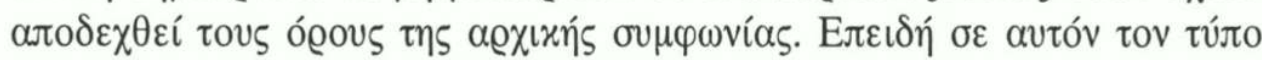

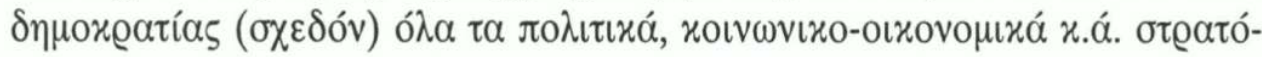

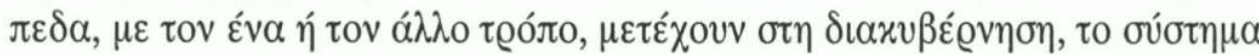

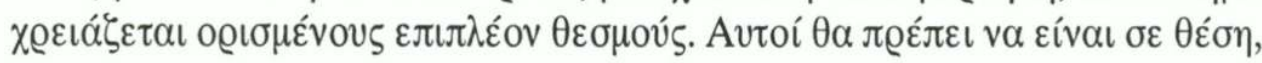




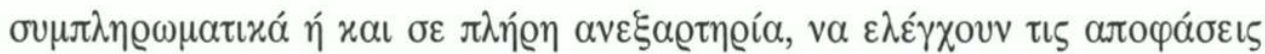

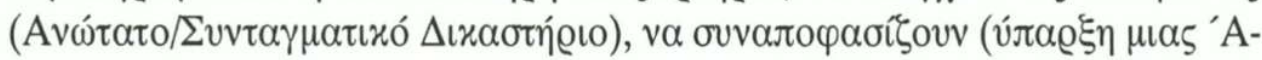

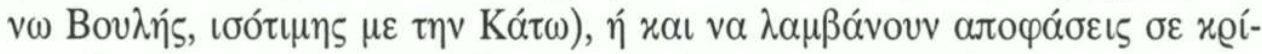

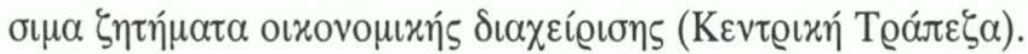

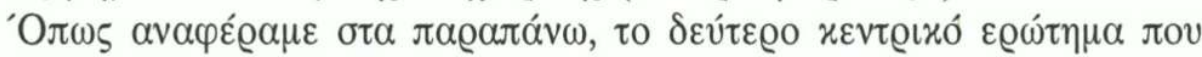

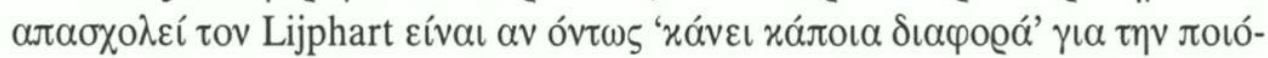

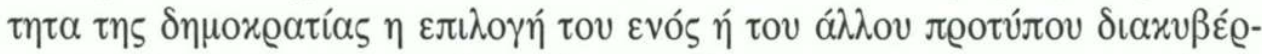

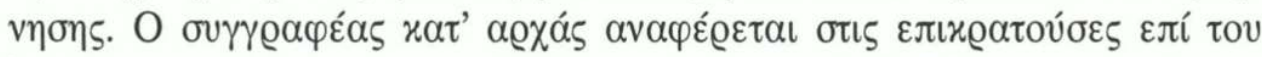

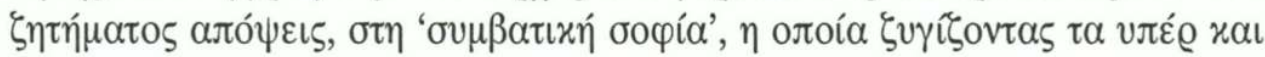

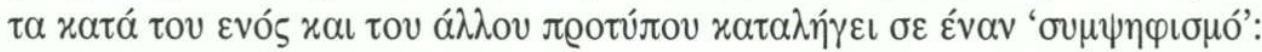

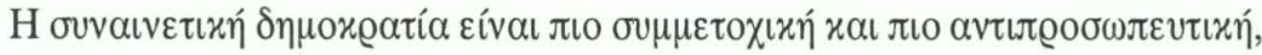

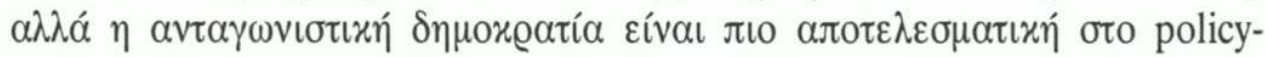

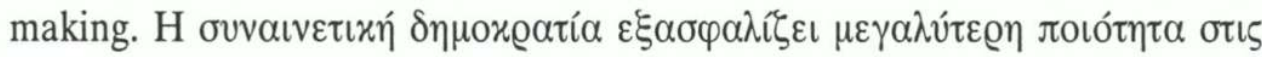

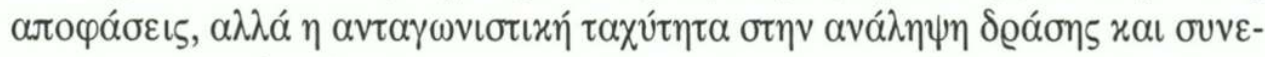

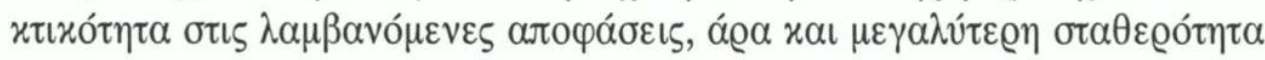

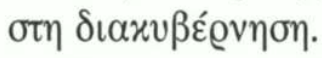

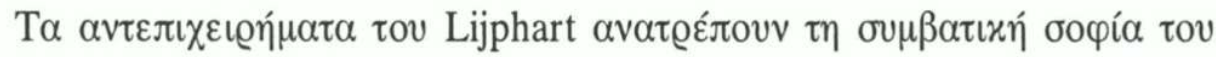

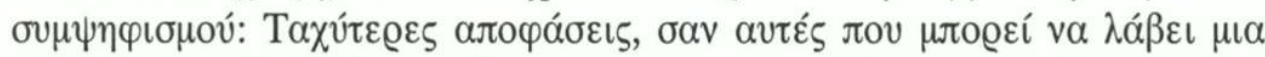

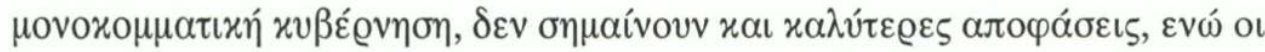

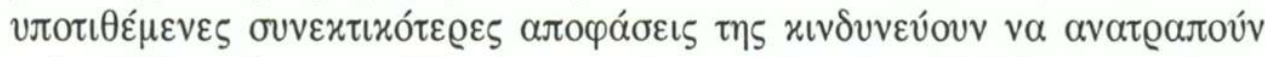

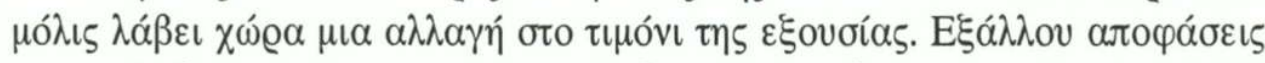

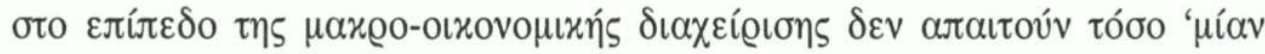

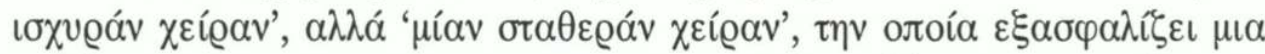

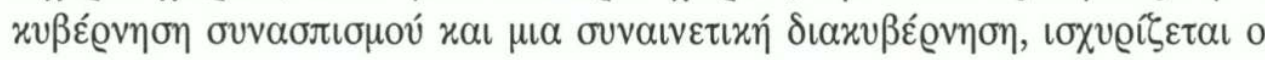

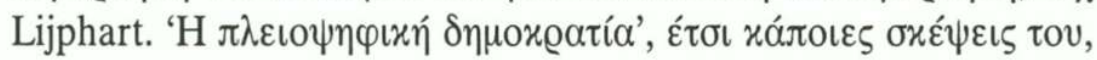

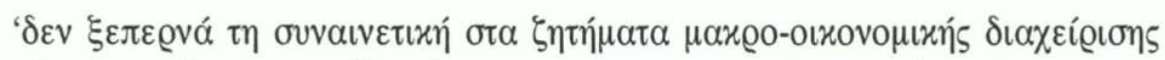

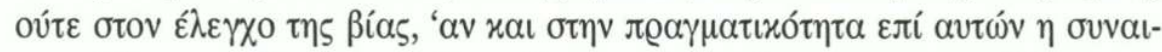

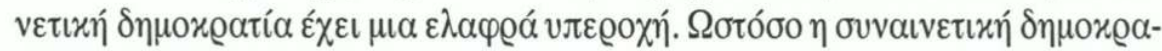

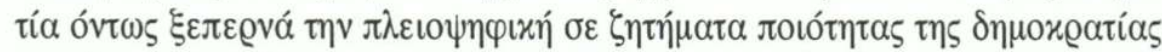

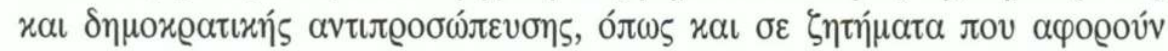

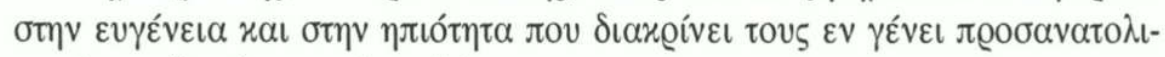

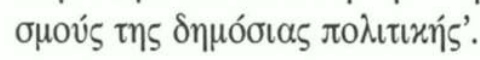

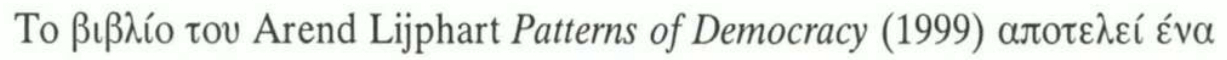

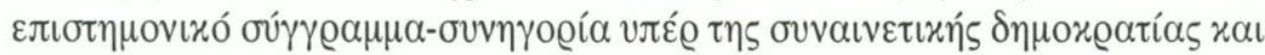

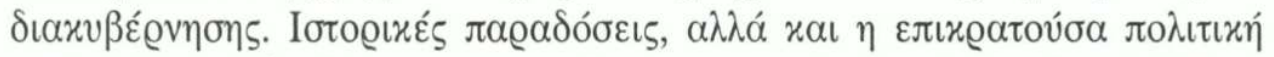

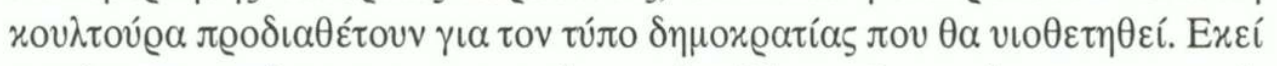

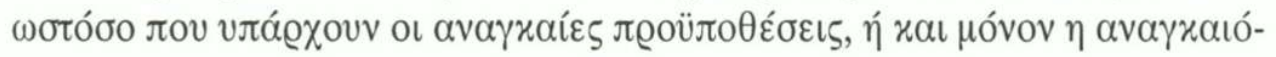




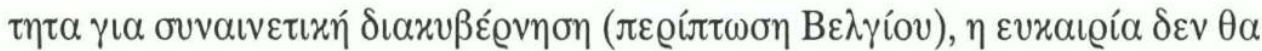

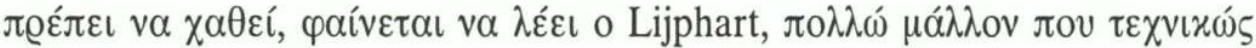

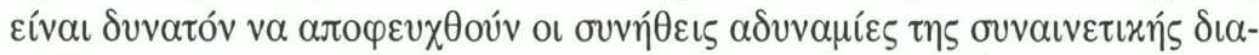

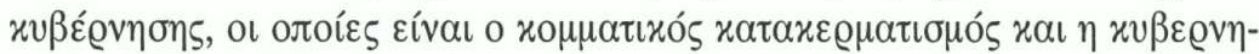

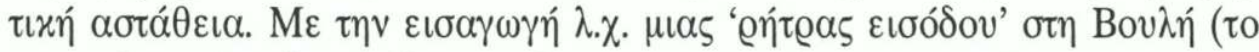

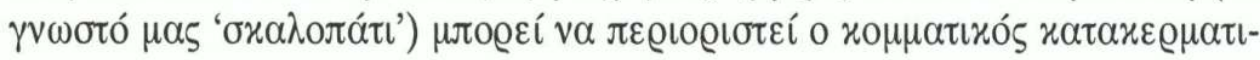

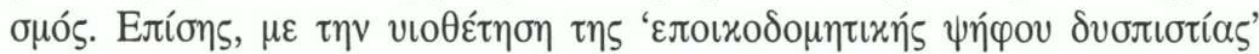

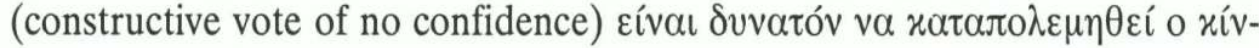

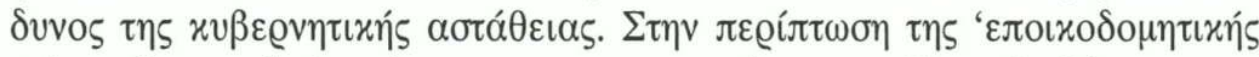

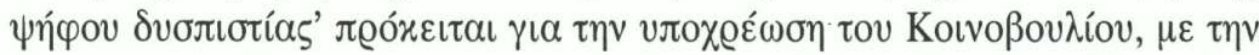

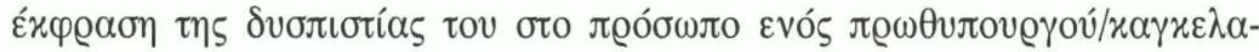

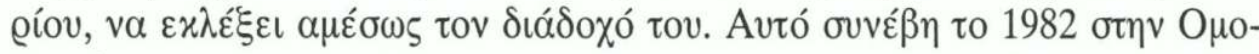

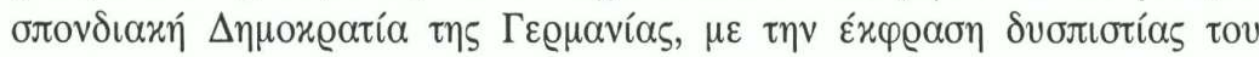

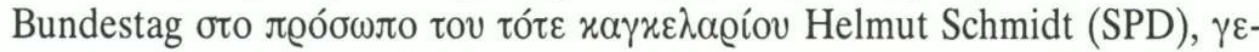

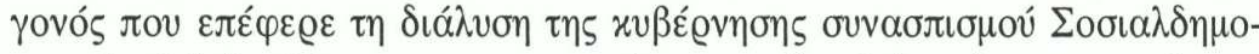

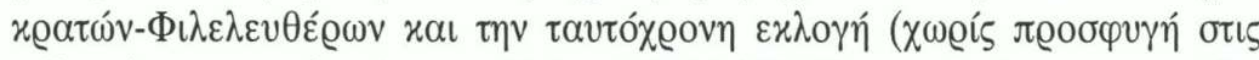

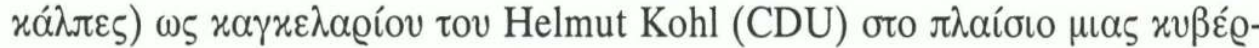

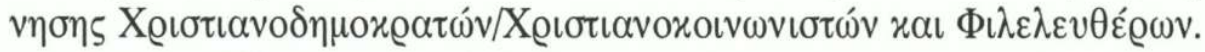

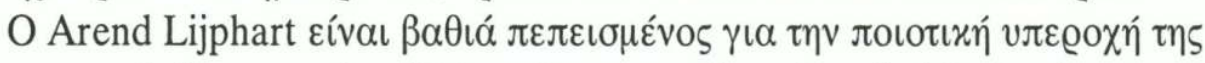

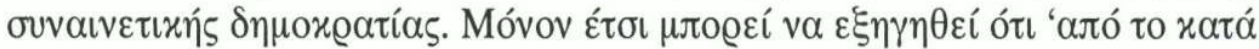

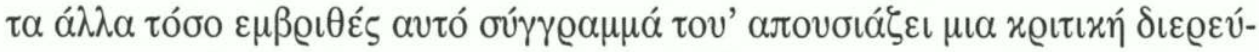

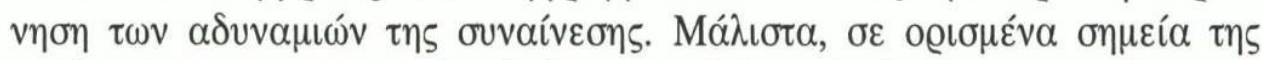

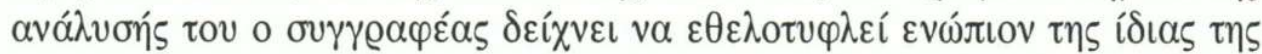

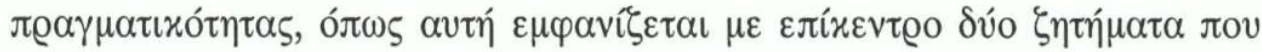

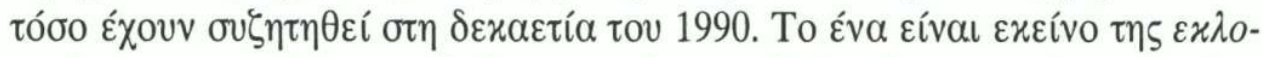

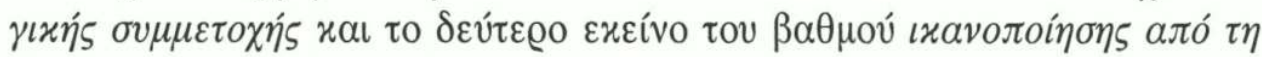

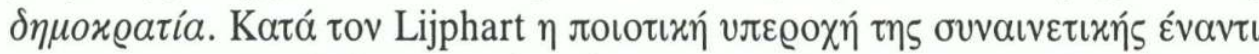

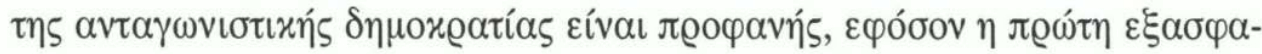

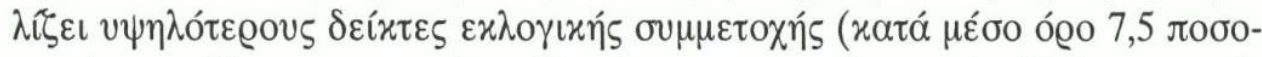

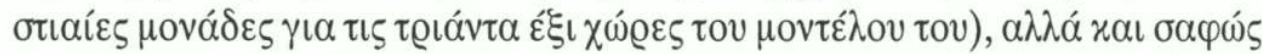

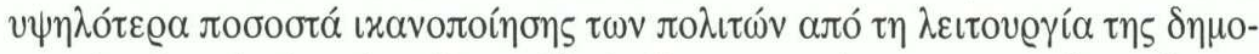

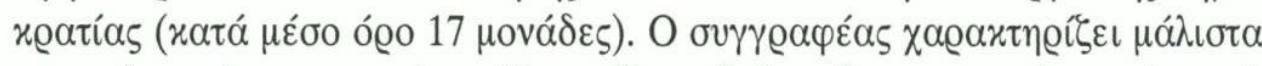

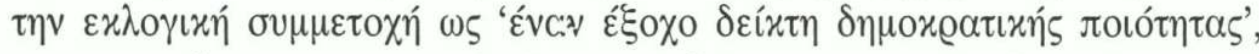

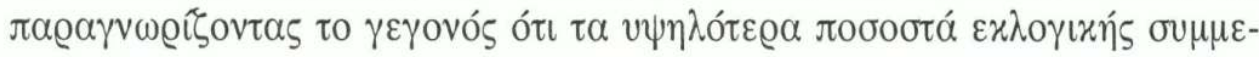

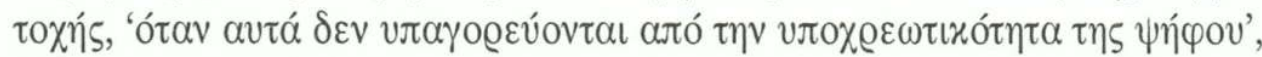

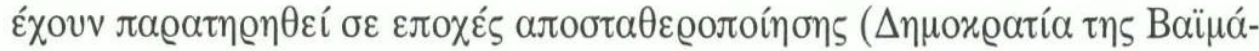

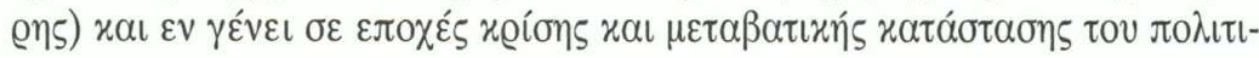




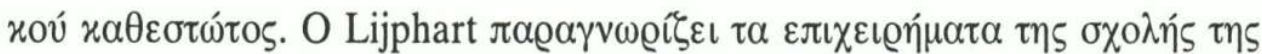

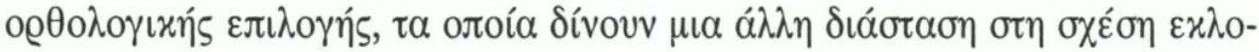

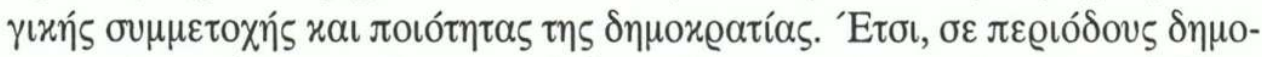

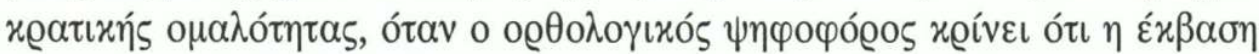

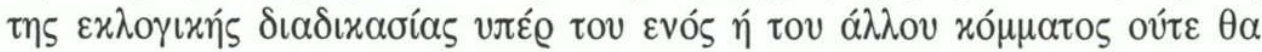

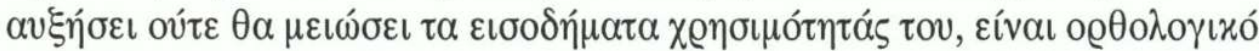

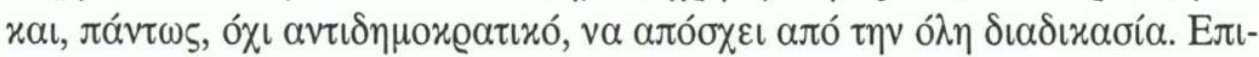

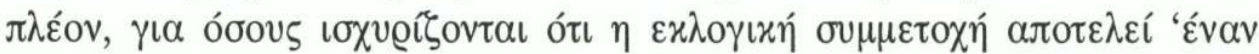

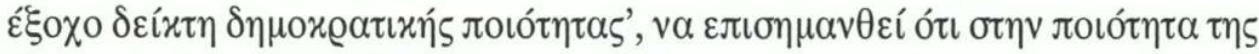

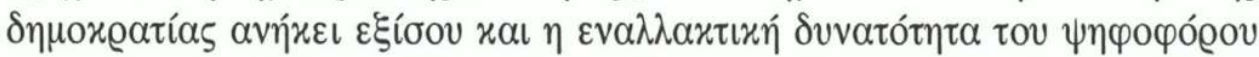

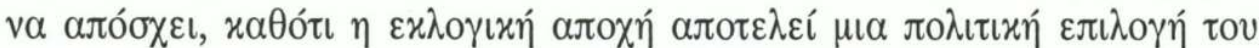

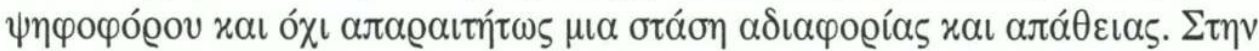

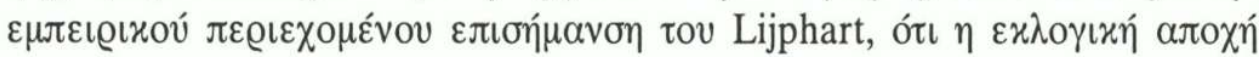

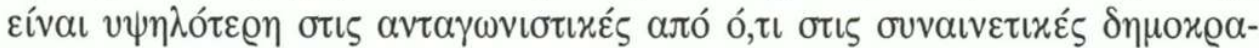

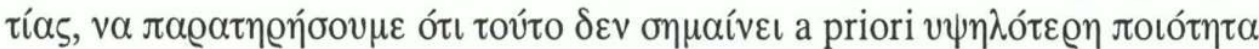

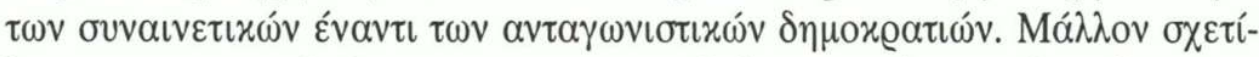

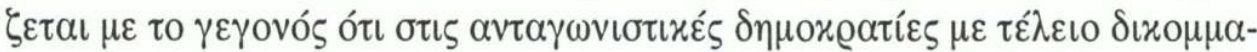

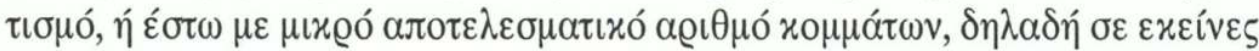

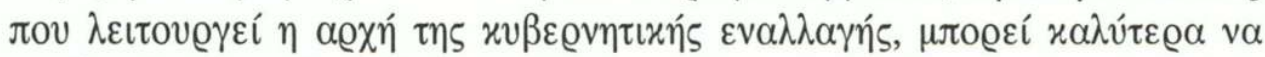

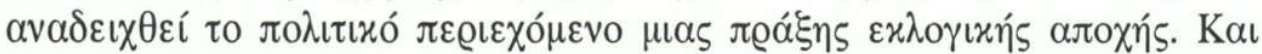

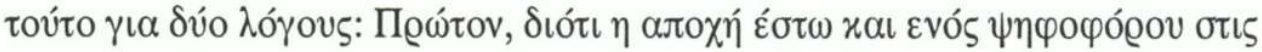

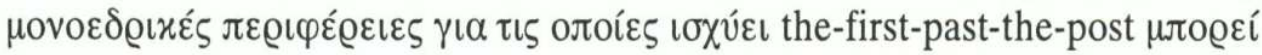

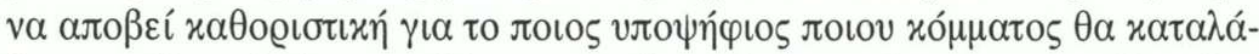

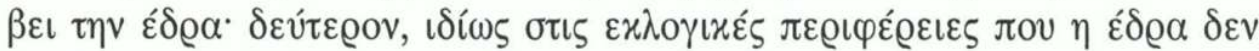

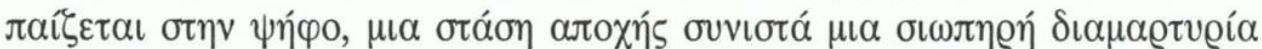

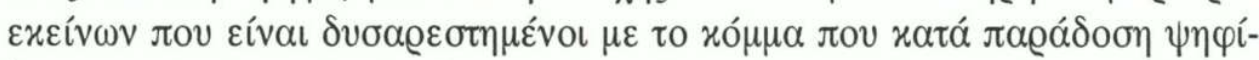

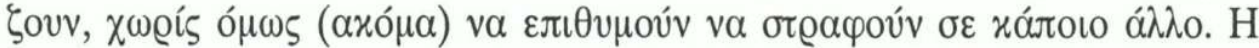

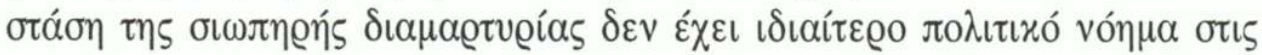

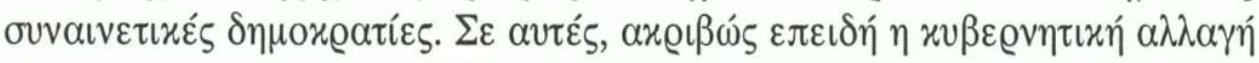

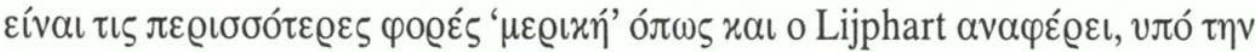

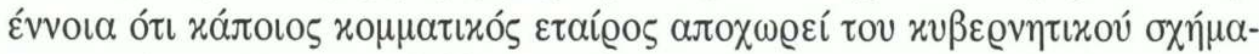

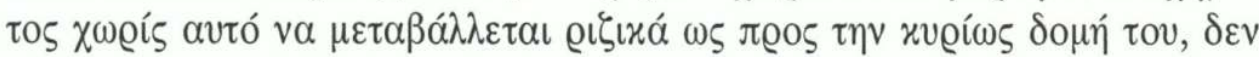

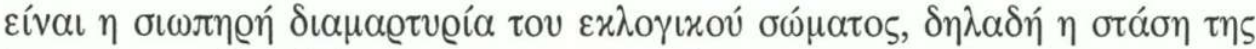

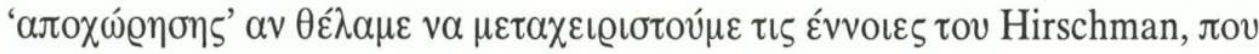

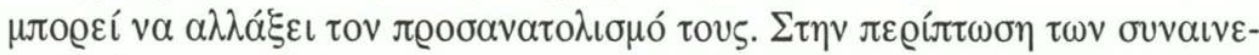

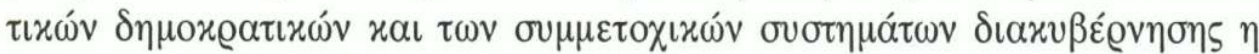

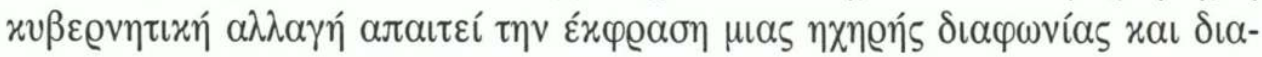




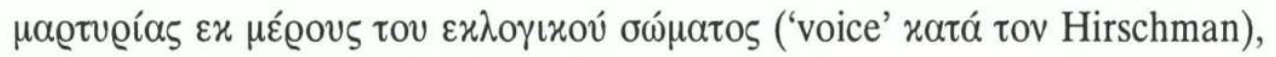

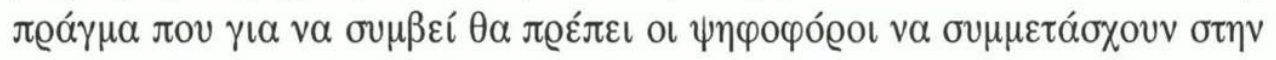

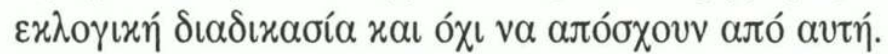

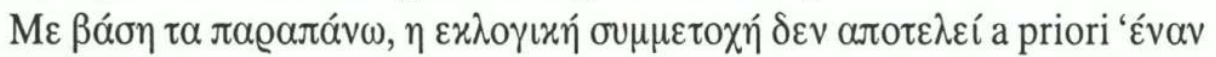

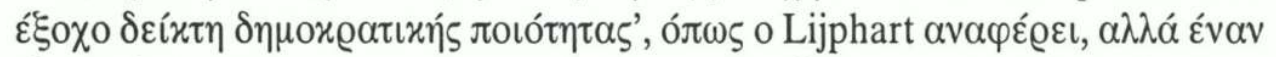

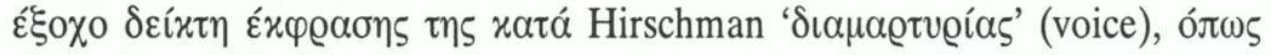

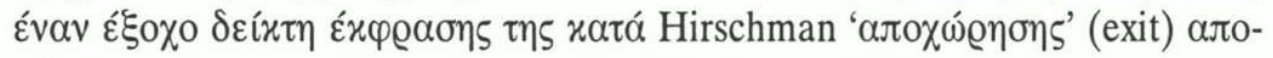

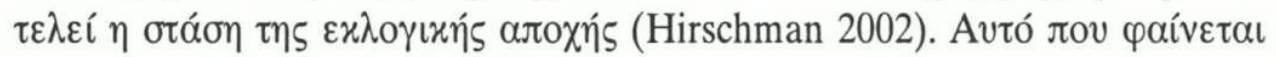

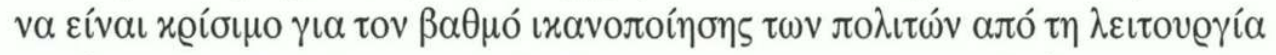

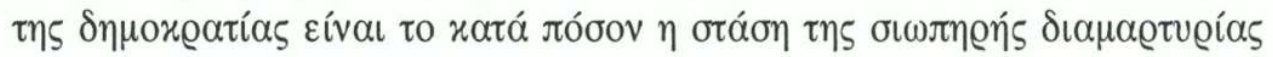

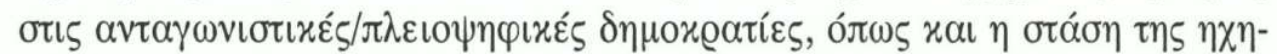

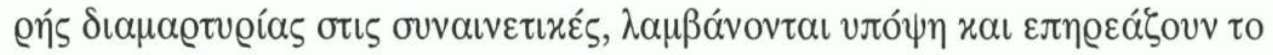

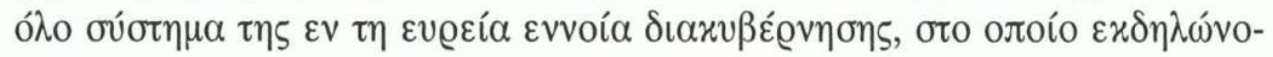

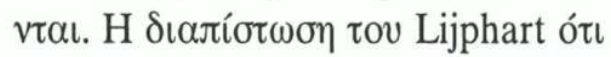

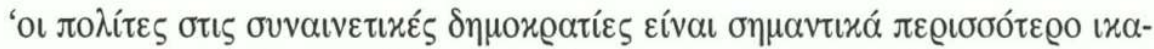

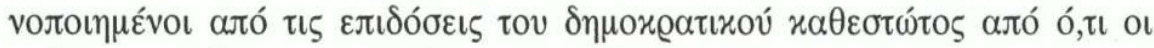

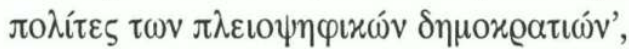

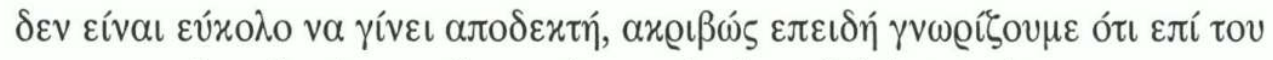

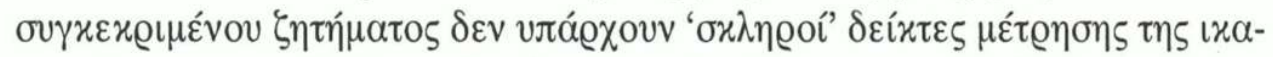

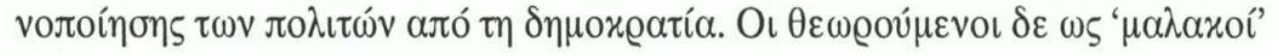

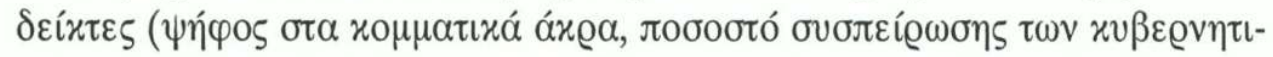

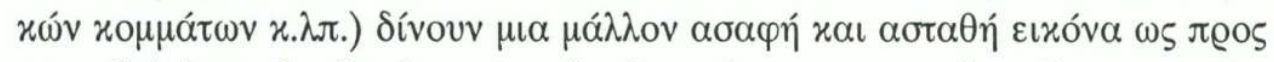

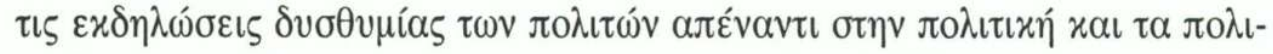

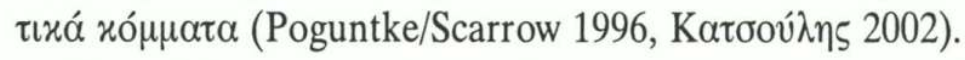

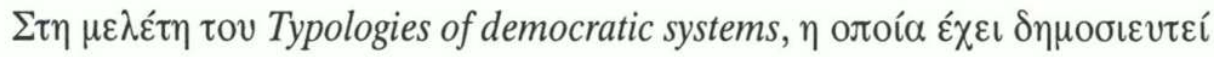

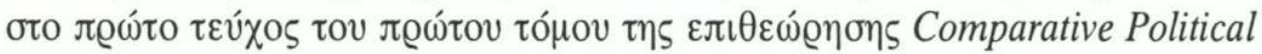

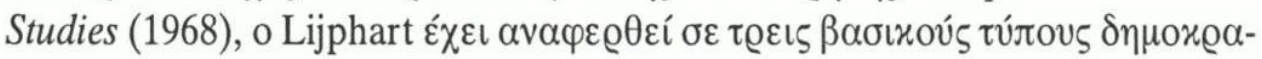

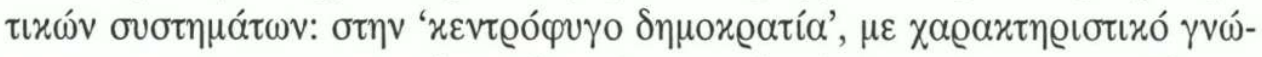

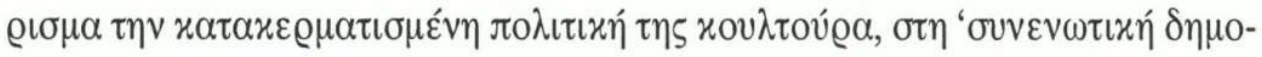

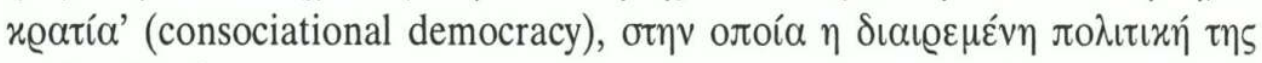

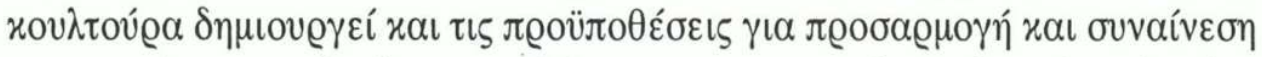

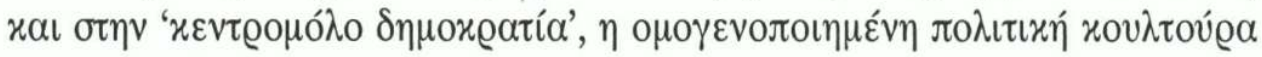

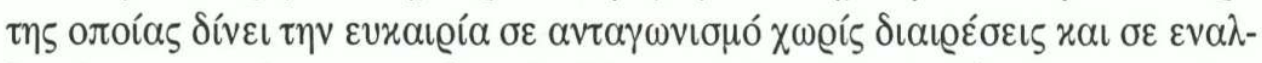

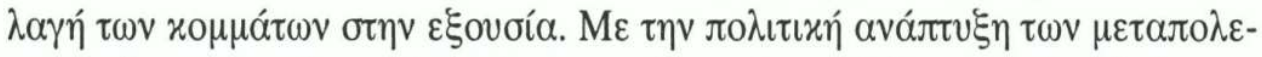

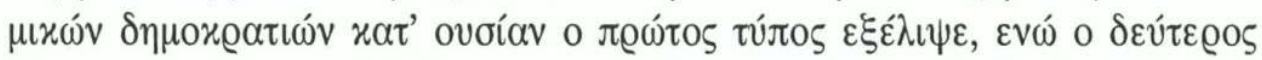

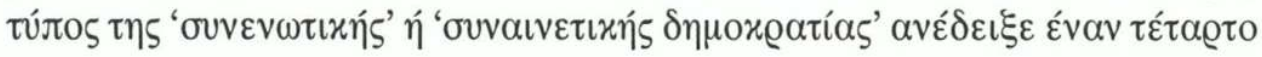




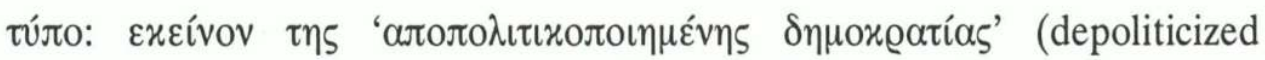

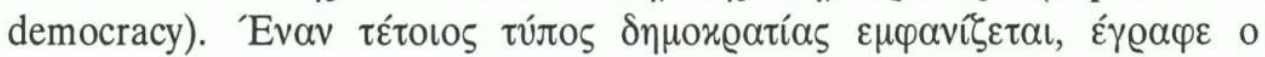

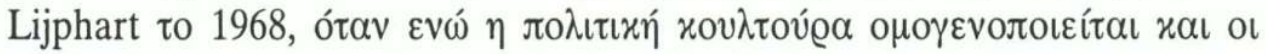

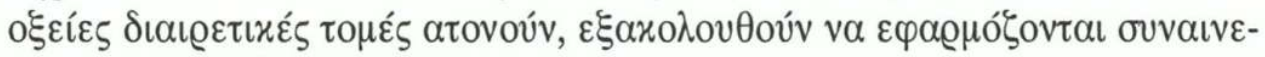

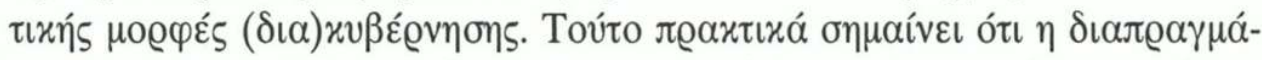

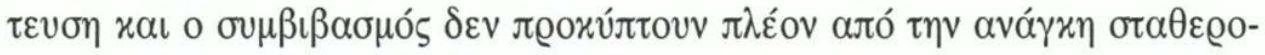

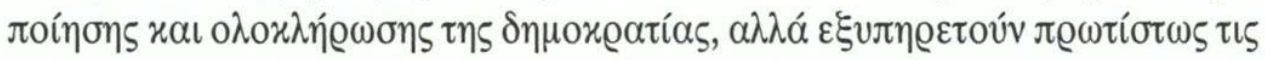

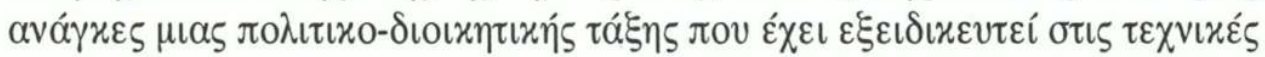

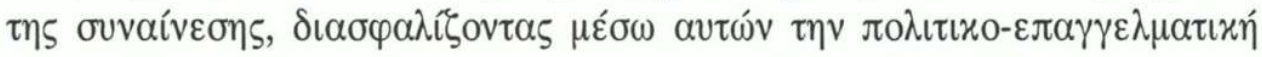

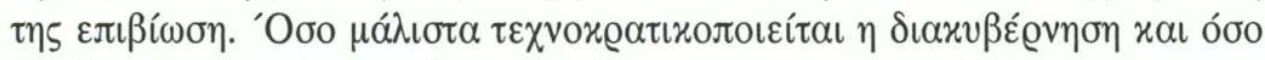

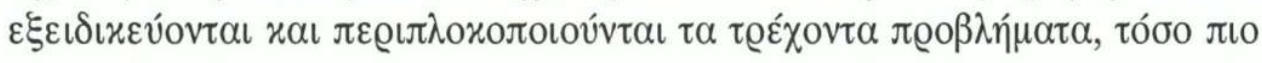

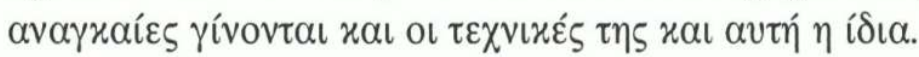

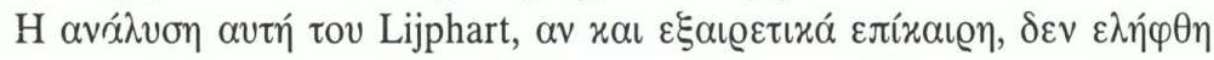

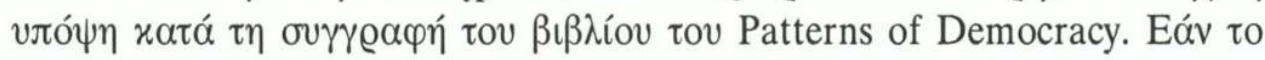

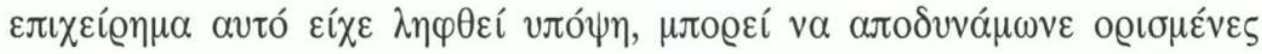

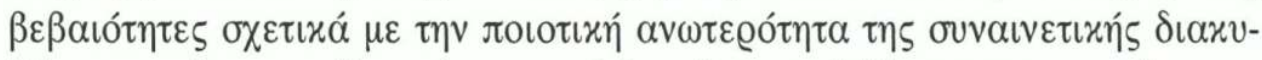

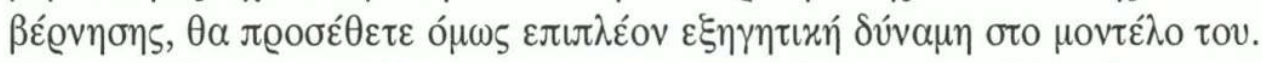

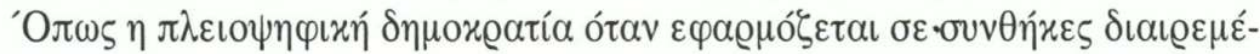

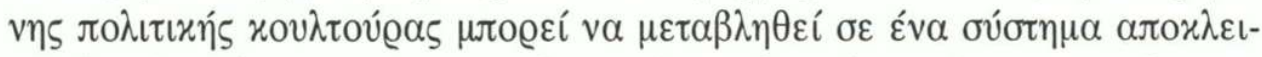

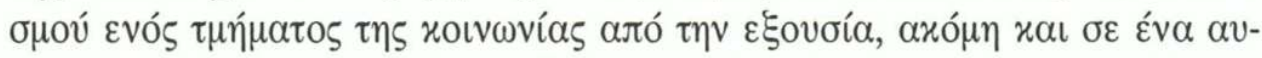

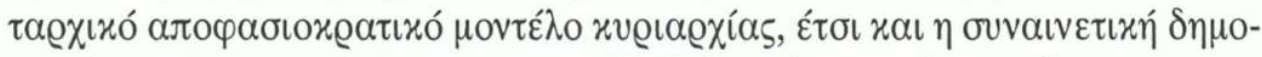

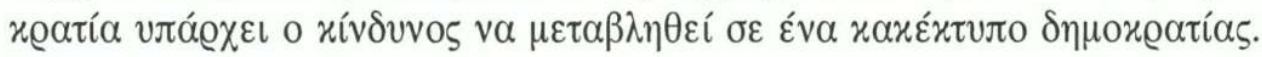

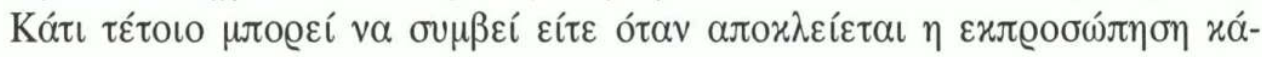

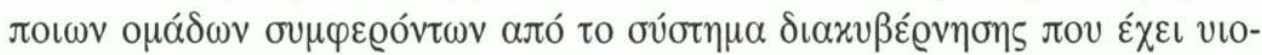

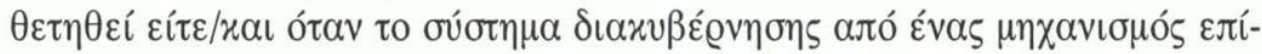

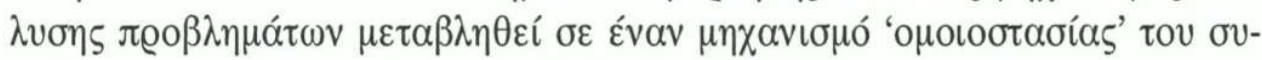

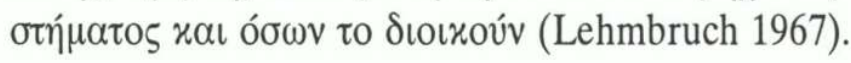

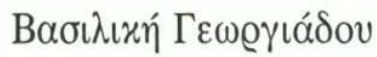

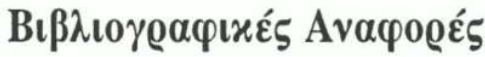

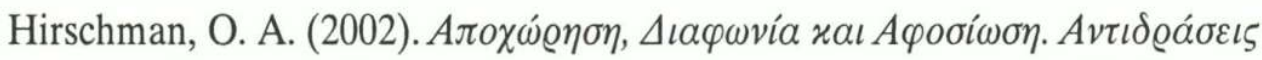

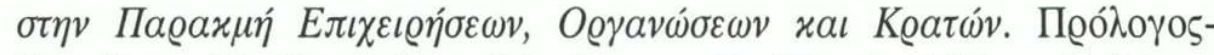

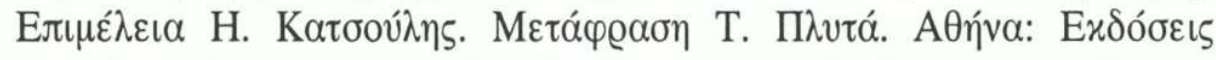

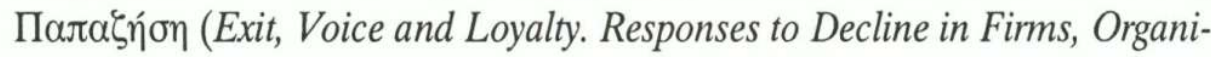
zations and States. Harvard University Press 1970). 


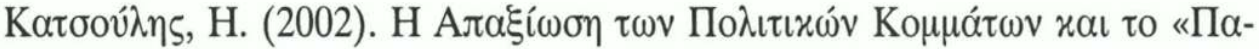

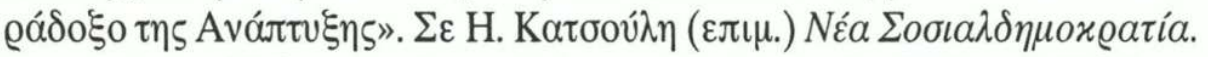

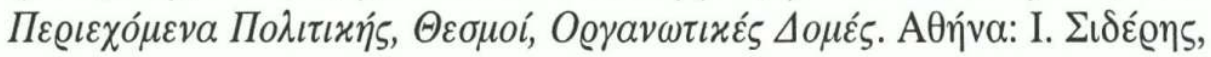
15-76.

Lehmbruch, G. (1967). Proporzdemokratie. Politisches System und Politische Kultur in der Schweiz und in Österreich. Tübingen: J.C.B. Mohr (Paul Siebeck).

Lijphart, A. (1984). Democracies. Patterns of Majoritarian and Consensus Government in Twenty-One Countries. New Haven and London: Yale University Press.

Lijphart, A. (1968). 'Typologies of Democratic Systems'. Comparative Political Studies, 1, 1: 3-44.

Poguntke, T. \& Scarrow, S. (eds.) (1996). The Politics of Anti-Party Sentiment. European Journal of Political Research (Special Issue), 29, 3.

Richard A. Posner, Law, economics and democracy: Three lectures in Greece,

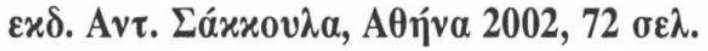

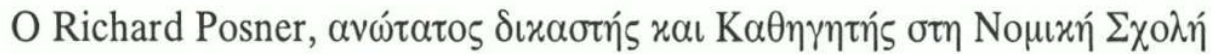

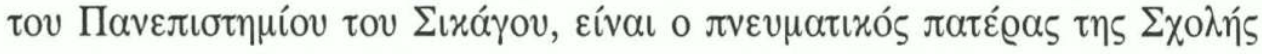

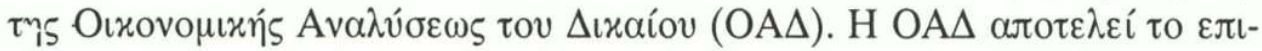

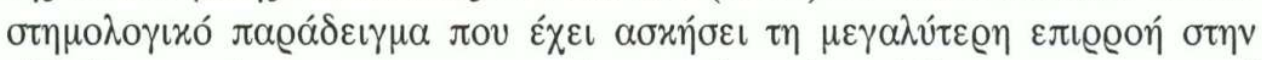

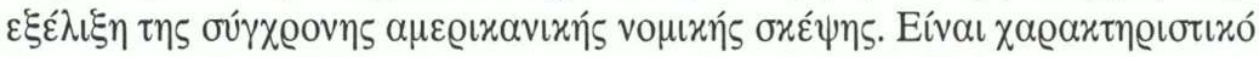

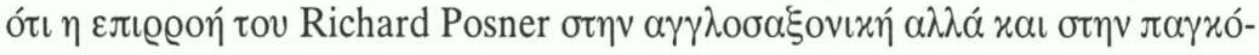

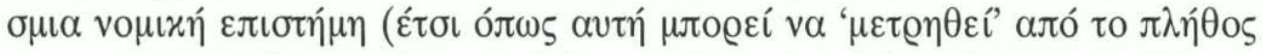

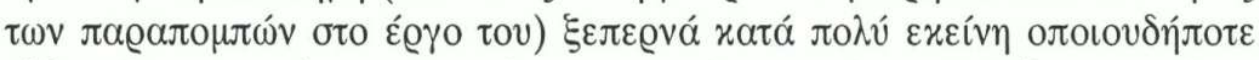

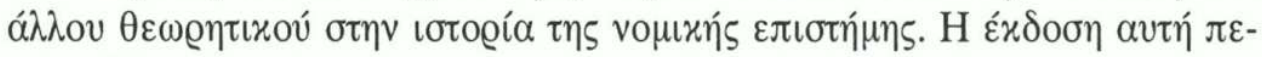

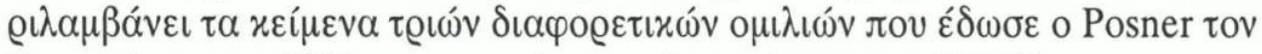

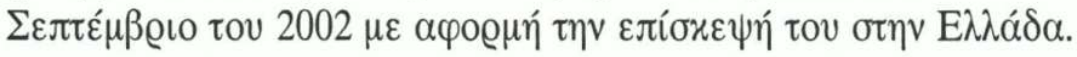

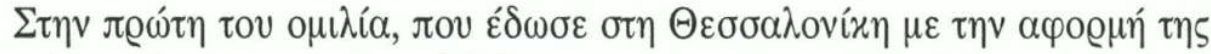

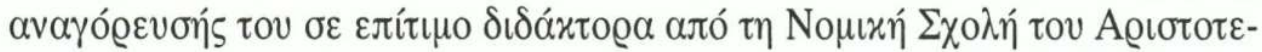

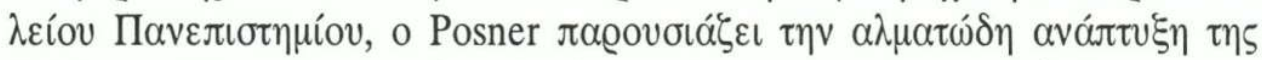

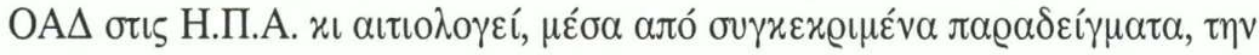

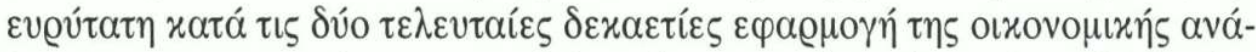

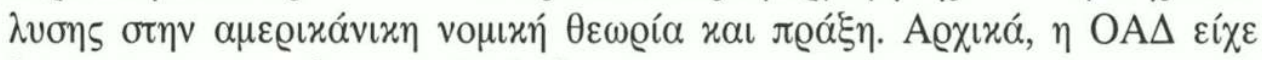

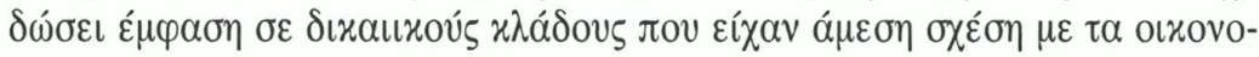

